\title{
Health of workmen in the chromate-producing industry in Britain
}

\author{
M R ALDERSON, N S RATTAN, AND L BIDSTRUP \\ From the Division of Epidemiology, Institute of Cancer Research, Sutton, Surrey SM2 5PX, and \\ London SWIX 9DG, UK
}

\begin{abstract}
In a follow-up study of 2715 men who had worked for at least one year at the three chromate-producing factories in Britain between 1948 and 1977 only 298 were lost to follow-up, and the average number of person-years in the study was $16 \cdot 3$. One hundred and sixteen deaths from lung cancer occurred in these men, with only 48.0 expected $(\mathrm{O} / \mathrm{E}=2.4 ; \mathrm{p}<0.001)$. For men employed at the factory, which is still in operation, the relative risk of lung cancer has decreased from over 3.0 before plant modification to about 1.8 in those who have worked only since plant modification. A multivariate analysis was used in an attempt to unravel the overlapping influence of duration of employment, length of follow-up, plant modification, factory, age at entry to work, and estimated degree of chromate exposure. The major independent factor appeared to be duration of employment; in addition the analysis suggested that modifications in the plant and work environment had been associated with an appreciable reduction of the excess risk from lung cancer.
\end{abstract}

Cases of lung cancer were reported among workers engaged in manufacturing basic chromates in Germany in the early part of this century. ${ }^{1}$ Machle and Gregorius ${ }^{2}$ compared the pattern of mortality among 1445 United States workers in the chromateproducing industry in the 1940 s with that of Metropolitan Life Insurance policy holders. The proportion of deaths from respiratory cancer was appreciably raised in those engaged in the production of dichromates. A review showed 122 case reports of pulmonary carcinoma in chromate workers: one each from England and Switzerland, with the remainder from Germany and the United States.

Other epidemiological studies carried out in the past 30 years in the United States ${ }^{3-6}$ and Japan ${ }^{7}$ have confirmed an excess risk from lung cancer in the industry, although the estimates of the actual relative risk have varied.

After the findings of Machle and Gregorius, ${ }^{2}$ an investigation of the possible risk in the industry in Britain was started in the 1940s. Bidstrup ${ }^{9}$ published the results of a clinical and radiographic investigation of all men employed at that time in the three factories concerned. Altogether 724 workmen were

Received 20 February 1980

Accepted 16 June 1980 interviewed and radiographed; one man had carcinoma of the lung from which he subsequently died.

The original survey was later extended with follow-up examination of the mortality of the men until 1955.10 The company notified Bidstrup and Case whenever a man left employment and gave the reason. For those who died the cause of death was established; for those who retired periodic radiography was offered, and contact was maintained in this way. At this stage it was not feasible to follow up those who had left to seek other employment. This second study showed an excess of lung cancer, 12 deaths being found against an expected number of $3.3(p=0.005)$. There was little difference between the observed and expected figures for neoplasms at other sites (observed $=9$, expected $=7.9$ ) nor for other causes of death (observed $=38$, expected $=36 \cdot 3$ ). The authors believed that there was no evidence that the increase in lung cancer could be attributed to place of residence, social class, or smoking habits. They also suggested that it would be inappropriate to consider that the excess was due to diagnostic bias, and concluded that carcinoma of the lung was an occupational hazard in the chromate-producing industry in Britain. The relative excess was 3.6 ; this is very different from the suggested figure from America ${ }^{2}$ of a 25 -fold excess. Bidstrup and Case, ${ }^{10}$ however, pointed out that it is 
inappropriate to compare estimates of relative risk from incomplete experience of limited follow-up of different cohorts.

Since 1956, annual radiography (and since 1961 radiography at intervals of eight months) has been offered to all employees in the factories concerned, all men who have retired, and all those leaving the industry after a minimum of five years' continuous service. A supplementary report (RAM Case, unpublished findings) commented on a modest excess of deaths from bronchitis; 18 deaths were observed while 11.4 were expected. It was pointed out that it was difficult to assess the significance of this excess of deaths from bronchitis in relation to the possible aetiology of the deaths from lung cancer. In the same report some data were presented on the smoking habits of employees; only just over $70 \%$ of the men completed a questionnaire. The percentage of heavy smokers was lower than that reported for England and Wales, ${ }^{11}$ and there was no evidence from the respondents of a major risk for lung cancer due to excess smoking, compared with the population as a whole. This supported the earlier contention that the excess mortality from lung cancer was not due to excessive cigarette smoking.

In addition to carrying out regular radiographic surveys, sputum cytology was introduced between 1958 and 1961 , when about 500 sputum specimens were examined from employees absent from work with respiratory complaints. The results of these investigations were all negative, and this approach was abandoned as a means of detecting early and potentially curable lung cancer. Pre-employment and postsickness examinations were introduced from 1956.

We now report a further follow-up study of these workers.

\section{Process in the factories}

The works concerned started producing chromates in 1893 at Bolton, in 1930 at Rutherglen, and in 1927-8 at Eaglescliffe. Production was terminated at Bolton in 1966, at Rutherglen in 1967, and rationalised and concentrated at Eaglescliffe.

The initial stage in manufacture is the conversion of insoluble chromium in the ore chromite. Until the late 1950s all three works operated a "high-lime" process in which the insoluble $\mathrm{Cr}_{2} \mathrm{O}_{3}$ was converted to soluble sodium chromate, but some relatively slowly soluble calcium chromate was formed also. A range of chromium chemicals is produced.

At Bolton and Rutherglen, hand-fired furnaces were used until the early 1940 s when rotary kilns were introduced. The exposure to raw materials and "first" product (sodium chromate and some calcium chromate) would have been much greater from hand-fired furnaces than from the rotary kilns that were always used at Eaglescliffe.

From 1954 onwards, major changes in handling raw materials, intermediates, and finished products were made-mechanisation of the preparation and handling of raw materials; improvements in sealing the kiln gas entry to flues; installation of electrostatic dust precipitators in the flue systems of the kilns; mechanical handling of residue in a totally enclosed system; and mechanisation and ventilation to eliminate dust, mist, and vapour in the leaching of sodium chromate.

The major change was the successful development in 1957-9 of the "no-lime" process that was introduced at Eaglescliffe, and by 1961 all production there was by this process. Rutherglen operated a "low-lime" process from 1957 to 1959 until closure in 1967, but Bolton did not change. A continuous process was introduced in which the roast from the kilns dropped directly into enclosed tanks beneath the kilns and was pumped from there to the leaching plant. In the "no-lime" process insoluble materials are removed in the leaching plant by adjustment of $\mathrm{pH}$ and filtration. The pure sodium chromate is subsequently conveyed in an enclosed system for reaction with sulphuric acid.

Improvements in operating techniques have continued with emphasis at all stages on eliminating sources of exposure to airborne chrome-containing materials; this has been accompanied by a programme for training operatives. Routine atmosphere sampling, introduced in the early 1960s, monitors the effectiveness of changes in process and operating techniques.

\section{Method}

Subjects were eligible for this study if they had had an $x$-ray examination at work (since 1956 all entrants have had pre-employment radiography) and had been in post for a minimum of one year's continuous service. The source of information was records accumulated by Bidstrup, who was responsible for the original survey of men in the late 1940s and since the mid-1950s has been responsible for supervising the health of all employees and exemployees.

About 500 men are employed at the remaining (Eaglescliffe) factory, including those transferred from other locations. Others were known to be alive because they were having regular radiography. Attempts have been made to follow up all other individuals who had left before retirement, or who had retired; where a National Insurance number was known but no NHS number these individuals have 
been traced through the social security division of the DHSS. Those men with no known NI numbers living in Scotland have been traced through the General Register Office (GRO) and in England through the Office of Population Censuses and Surveys (OPCS). Several individuals who could not be traced by GRO or OPCS have also had their particulars forwarded to DHSS; where the latter records showed that an individual had died, the death details were obtained from OPCS for deaths in England and Wales, or GRO for deaths in Scotland. These two offices also provided details of death for individuals whom they had traced and found to be dead. These details, obtained from the various sources of information, have been coded, using the rules obtaining at the time of death.

Because the follow-up study has now been extended, obtaining full identification details of the men who left employment several years ago has proved difficult, particularly for individuals who worked at Bolton and Rutherglen, which were closed down in the late 1960s. Minimum details were required about the work performed by each individual, so that their job could be classified into three broad categories of degree of exposure to chromate. In addition, date of joining the company and last date employed at one of the three factories was used to measure duration of exposure. It was not feasible to attempt to trace those individuals who lacked the minimum identification particulars required by DHSS, GRO, or OPCS. Other individuals had to be rejected from the study because of limited particulars about their employment, specifically the absence of detail of date of entry of employment or description of work carried out. Though information was available for women who have been employed by the company, they have not been included in the followup because of the small number concerned.

The data have been transcribed, punched, and submitted to a computer edit program. This checked that the dates of birth, entering employment, leaving employment, and last known date alive or date of death were valid and in the correct order. Various statistical distributions were examined to check that the file of data appears complete and valid; in particular the numbers in post each year have been examined by factory, with distribution of the age at entry, age at leaving, and duration of survival.

The data have been used to calculate person-years at risk, by means of a computer program MYCL (man-years computer language) written by Hill. ${ }^{12}$ Due to the entry criteria of a minimum of one year's continuous service, the first year of employment has been excluded from the person-years at risk calculations. The standard analysis taking sex, age, and calendar period into account has been performed to calculate expected deaths by cause. ${ }^{13}$

The national mortality rates for England and Wales have been used for Bolton and Eaglescliffe men, while rates for Scotland have been used for Rutherglen men. ${ }^{14}$ Where expected is greater than 5 , the difference between observed and expected has been tested by $\chi^{2}$; for expected less than 5 , the data have been treated as a Poisson variate and the probability of the same or a greater difference between observed and expected calculated.

The study started with a survey of all men in post in 1948-9, but then added all new employees after one year's employment with the company; the plants were modified in the 1950s, but those men ivilo worked only before these modifications had been carried out include a high proportion of men who had worked for many years. There is thus confounding between environmental change and duration of employment. One approach to this problem is to tabulate the data by two variates - calendar period of employment and duration of employment. Investigating this issue by splitting the tables into subgroups for each relevant variate, however, creates cells with fewer and fewer numbers. In an attempt to disentangle the influence of duration of employment from work before and after the plant modifications a multivariate analysis has been performed, based on the Feldstein ${ }^{15}$ multiple regression model. The data for each individual have been converted to binary scores for binary variates-for example, three categories of duration of employment were identified: $1-9$ years, $10-19$ years, more than 20 years. Each man was assigned a yes or no response to each of these three categories within duration of employment.

Each of the variates thought relevant to risk of lung cancer in this study was so handled: duration of employment-length of follow-up; calendar period of employment; that is, before major plant change, before and after plant change, after plant change; factory; age at first employment in factory; estimated degree of exposure to chromate. The dependant variate was death from lung cancer (yes/no for each individual). This enabled the independent contribution for each factor to "risk of lung cancer" to be examined.

\section{Results}

Table 1 shows the numbers included in the study and the status on follow-up. As already indicated, a proportion of the individuals had to be rejected because of inadequate basic information. Where adequate information was available, the trace rate is satisfactory; 602 subjects were found to have died, 
Table 1 Numbers of chromate workers employed during 1948-77, with follow-up status, by factory

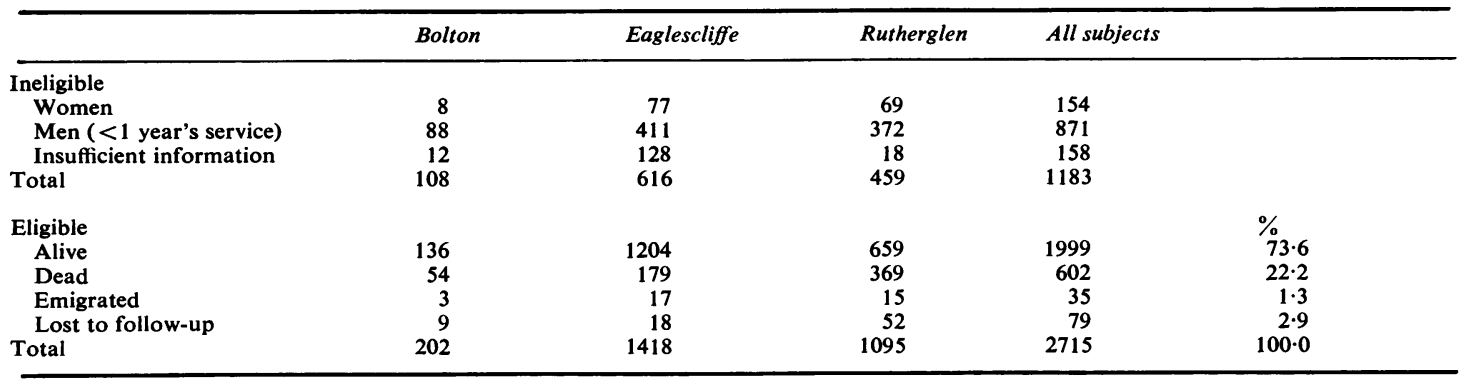

Table 2 Number of chromate workers included in analysis and average person-years at risk, by factory

\begin{tabular}{lcl}
\hline Factory & No of men & $\begin{array}{l}\text { Average person-years } \\
\text { of follow-up }\end{array}$ \\
\hline Bolton & 193 & $19 \cdot 1$ \\
Eaglescliffe & 1400 & $14 \cdot 5$ \\
Rutherglen & 1043 & $18 \cdot 2$ \\
All & 2636 & $16 \cdot 3$ \\
\hline
\end{tabular}

and it has not been possible to obtain the death details for five.

Table 2 shows details of the numbers of individuals included in the analyses by factory and the average follow-up; the average follow-up is longer at
Rutherglen and Bolton as these factories closed in the late 1960s, whereas individuals have been included in the study who have joined Eaglescliffe in the late 1960s and early 1970s.

Table 3 shows for each factory the observed and expected numbers of deaths for lung cancer, nasal cancer, other neoplasms, chronic bronchitis, all other causes of death, and all causes of death.

For all men in the study the total number of deaths observed from all causes was 602 with an expected figure of 445.3 giving a ratio of $\mathrm{O} / \mathrm{E}$ of 1.35 $(p \ll 0.001)$. The major contribution to the excess of deaths is lung cancer, which showed an excess at Bolton, Eaglescliffe, and Rutherglen; the ratios of O/E being $1.0,2.2(\mathrm{p} \ll 0.001)$, and $2.9(\mathrm{p} \ll 0.001)$.

Table 3 Observed and expected deaths in chromate workers by cause and factory, 1949-77

\begin{tabular}{|c|c|c|c|c|}
\hline & Bolton & Eaglescliffe & Rutherglen & All men \\
\hline \multicolumn{5}{|l|}{ Lung cancer } \\
\hline Observed: $O$ & 5 & 36 & 75 & 116 \\
\hline Expected: E & 4.98 & $16 \cdot 70$ & $26 \cdot 28$ & $47 \cdot 96$ \\
\hline O/E & 1.004 & $2 \cdot 156$ & 2.854 & $2 \cdot 419$ \\
\hline p & $<0.560$ & $\ll 0.001$ & $\ll 0.001$ & $\ll 0.001$ \\
\hline \multicolumn{5}{|l|}{ Nasal cancer } \\
\hline O & 0 & 0 & 2 & 2 \\
\hline $\mathbf{E}$ & 0.03 & $0 \cdot 10$ & $0 \cdot 15$ & $0 \cdot 28$ \\
\hline $\mathrm{O} / \mathrm{E}$ & & & 13.333 & $7 \cdot 143$ \\
\hline p & 0.970 & 0.905 & 0.010 & 0.033 \\
\hline \multicolumn{5}{|c|}{ Other neoplasms } \\
\hline o & 10 & 31 & 39 & 80 \\
\hline E & 6.78 & $23 \cdot 72$ & 38.95 & $69 \cdot 45$ \\
\hline $\mathrm{O} / \mathrm{E}$ & 1.47 & $1 \cdot 307$ & 1.001 & $1 \cdot 152$ \\
\hline p & $<0.206$ & $<0 \cdot 121$ & $<0.975$ & $<0.192$ \\
\hline \multicolumn{5}{|l|}{ Bronchitis } \\
\hline o & 3 & 5 & 31 & 39 \\
\hline E & 3.48 & $10 \cdot 79$ & $17 \cdot 40$ & $31 \cdot 67$ \\
\hline $\mathbf{O} / \mathbf{E}$ & 0.862 & 0.463 & 1.782 & $1 \cdot 231$ \\
\hline p & $0 \cdot 541$ & $<0.083$ & $<0.001$ & $<0.206$ \\
\hline \multicolumn{5}{|c|}{ All other causes } \\
\hline o & 36 & 107 & 222 & 365 \\
\hline $\mathbf{E}$ & $30 \cdot 88$ & 108.61 & 156.49 & 295.98 \\
\hline $\mathrm{O} / \mathrm{E}$ & $1 \cdot 166$ & 0.985 & 1.419 & 1.233 \\
\hline p & $<0.371$ & $<0.888$ & $\ll 0.001$ & $\ll 0.001$ \\
\hline \multicolumn{5}{|l|}{ All causes } \\
\hline O & 54 & 179 & 369 & 602 \\
\hline & $46 \cdot 15$ & 159.92 & $239 \cdot 27$ & $445 \cdot 34$ \\
\hline $\mathrm{O} / \mathrm{E}$ & $1 \cdot 17$ & $1 \cdot 119$ & 1.54 & 1.352 \\
\hline p & $<0.254$ & $<0.138$ & $\ll 0.001$ & $\ll 0.001$ \\
\hline
\end{tabular}


Table 4 Observed and expected deaths in chromate workers at Eaglescliffe by cause and period of employment

\begin{tabular}{|c|c|c|c|c|}
\hline & \multicolumn{4}{|c|}{ Duration of employment } \\
\hline & Prechange & Prelpostchange & Postchange & All period \\
\hline \multicolumn{5}{|c|}{ Lung cancer } \\
\hline $\mathrm{O}$ & 7 & 27 & 2 & 36 \\
\hline $\mathbf{E}$ & $2 \cdot 31$ & $13 \cdot 32$ & $1 \cdot 07$ & $16 \cdot 70$ \\
\hline $\mathrm{O} / \mathrm{E}$ & 3.030 & $2 \cdot 027$ & $1 \cdot 869$ & $2 \cdot 156$ \\
\hline p & $0 \cdot 009$ & $<0.001$ & $0 \cdot 290$ & $\ll 0.001$ \\
\hline \multicolumn{5}{|c|}{ Nasal sinus } \\
\hline $\mathbf{O}$ & 0 & 0 & 0 & 0 \\
\hline $\begin{array}{l}E \\
O / E\end{array}$ & 0.01 & 0.08 & $0 \cdot 01$ & $0 \cdot 10$ \\
\hline $\mathrm{p}$ & 0.990 & 0.923 & $0 \cdot 990$ & 0.905 \\
\hline \multicolumn{5}{|c|}{ Other neoplasms } \\
\hline $\mathbf{O}$ & 10 & 21 & 0 & 31 \\
\hline E & $3 \cdot 35$ & $18 \cdot 59$ & $1 \cdot 78$ & $23 \cdot 72$ \\
\hline $\mathrm{O} / \mathrm{E}$ & $2 \cdot 985$ & $1 \cdot 130$ & & $1 \cdot 307$ \\
\hline p & $<0.003$ & $<0.584$ & $0 \cdot 169$ & $0 \cdot 121$ \\
\hline \multicolumn{5}{|c|}{ Bronchitis } \\
\hline $\mathrm{O}$ & 1 & 4 & $\mathbf{0}$ & 5 \\
\hline E & 1.47 & $8 \cdot 87$ & 0.45 & $10 \cdot 79$ \\
\hline $\mathrm{O} / \mathrm{E}$ & 0.680 & 0.451 & & 0.463 \\
\hline p & $0 \cdot 568$ & $<0.107$ & 0.638 & 0.083 \\
\hline \multicolumn{5}{|c|}{ All other causes } \\
\hline O & 22 & 77 & 8 & 107 \\
\hline $\mathbf{E}$ & $14 \cdot 81$ & $85 \cdot 60$ & $8 \cdot 20$ & $108 \cdot 61$ \\
\hline $\mathbf{O} / \mathbf{E}$ & 1.485 & 0.900 & 0.976 & 0.985 \\
\hline p & $<0.065$ & $<0.371$ & $<0.950$ & $<0.888$ \\
\hline \multicolumn{5}{|c|}{ All causes } \\
\hline $\mathbf{O}$ & 40 & 129 & 10 & 179 \\
\hline E & $21 \cdot 95$ & $126 \cdot 46$ & $11 \cdot 51$ & $159 \cdot 92$ \\
\hline $\mathrm{O} / \mathrm{E}$ & $1 \cdot 822$ & $1 \cdot 020$ & 0.869 & $1 \cdot 119$ \\
\hline $\mathrm{p}$ & $\ll 0.001$ & $<0.823$ & $<0.752$ & $<0.138$ \\
\hline
\end{tabular}

There were only two deaths from nasal cancer, both occurring in men from Rutherglen; the excess at this location (and for all men in the study) was significant, though based on small numbers. There was a slight excess of all other neoplasms at the three locations, but this did not reach the conventional level of significance (for all men in the study, $p<0.192$ ).

Far fewer deaths resulted from chronic bronchitis than lung cancer, and the observed deaths at Bolton and Eaglescliffe were lower than expected. At Rutherglen there was an excess of deaths from chronic bronchitis with a ratio of $\mathrm{O} / \mathrm{E}$ of 1.8 $(p<0.001)$. There was an excess of deaths from all other causes at Bolton and Rutherglen, but this was quite probably due to chance at Bolton. There was a $40 \%$ excess in the Rutherglen men, however-a difference unlikely to be due to chance $(p<0.001)$.

There is interest in examining the relative risk of disease in men in the earlier study; particularly for men who have been employed at Eaglescliffe, the only factory now functioning. Table 4 sets out comparable data to table 3 ; it is restricted to Eaglescliffe, but presents data for those who worked (a) only before the plant modification, (b) both before and after the modifications, and (c) only after the modifications were completed. Some of these sets of figures are based on small numbers of observed deaths; especially those for the "post-modification" group, who have a lower average age and shorter follow-up. The data for lung cancer suggest that the relative risk has decreased from over three to less than two over the period of the plant modification. There is, however, confounding between the age distribution of the workforce, duration of employment, duration of follow-up, and the influence of environmental control. In an attempt to disentangle these and other factors a multivariate analysis has been performed.

Table 5 shows the results of the multivariate analysis; the size of the coefficients may be taken as a measure of the influence of each specific category within each of the variates on risk of lung cancer, independent of the influence of the other factorsfor instance, the influence of "period of employment -prechange" is calculated after adjusting for the variation in duration of work of these men.

In general, there appears to be an appreciable effect from duration of employment, duration of follow-up, working before or after plant modification, and specific factory; much less influence is due to age at entry or estimated degree of chromate exposure.

\section{Discussion}

Before attempting to interpret the results, it is important to consider some general caveats about 
Table 5 Independent contribution of various factors to risk of lung cancer in chromate workers

\begin{tabular}{|c|c|c|c|c|}
\hline Factor & Category & $\begin{array}{l}\text { Total No of men } \\
\text { in category }\end{array}$ & $\begin{array}{l}\text { Independent* } \\
\text { contribution to risk } \\
\text { of lung cancer }\end{array}$ & Overall range of factor \\
\hline Duration of employment (yr) & $\begin{array}{l}\leqslant 9 \\
10- \\
>20\end{array}$ & $\begin{array}{r}1565 \\
516 \\
555\end{array}$ & $\left.\begin{array}{r}-59 \\
+2 \\
+164\end{array}\right\}$ & 223 \\
\hline Duration of follow-up (yr) & $\begin{array}{l}\leqslant 9 \\
10- \\
>20\end{array}$ & $\begin{array}{r}541 \\
838 \\
1257\end{array}$ & $\left.\begin{array}{l}+118 \\
+56 \\
-88\end{array}\right\}$ & 206 \\
\hline Calendar period of employment & $\begin{array}{l}\text { Prechange } \\
\text { Pre/postchange } \\
\text { Postchange }\end{array}$ & $\begin{array}{r}542 \\
1202 \\
892\end{array}$ & $\left.\begin{array}{l}+73 \\
+50 \\
-112\end{array}\right\}$ & 185 \\
\hline Factory & $\begin{array}{l}\text { Bolton } \\
\text { Eaglescliffe } \\
\text { Rutherglen }\end{array}$ & $\begin{array}{r}193 \\
1400 \\
1043\end{array}$ & $\left.\begin{array}{l}-96 \\
-33 \\
+62\end{array}\right\}$ & 158 \\
\hline Entry age & $\begin{array}{l}\leqslant 25 \\
26- \\
>41\end{array}$ & $\begin{array}{r}938 \\
1187 \\
511\end{array}$ & $\left.\begin{array}{l}-20 \\
-6 \\
+50\end{array}\right\}$ & 70 \\
\hline Estimated degree of chromate exposure & $\begin{array}{l}\text { Negligible } \\
\text { Moderate } \\
\text { Major }\end{array}$ & $\begin{array}{r}171 \\
1066 \\
1399\end{array}$ & $\left.\begin{array}{r}-48 \\
+\quad 9 \\
-\quad 1\end{array}\right\}$ & 57 \\
\hline
\end{tabular}

* Scores given may be directly compared one with another to indicate magnitude of each category within factor to risk of lung cancer. Scores may be thought of as approximately indicating percentage variation from average risk of lung cancer for all men in study.

the data used. Both the observed and expected mortality depend on death certificates. This approach is accepted practice, ${ }^{17}$ though several studies have indicated that caution is required in interpreting the results. ${ }^{13}$ National mortality rates may be inappropriate for calculating expected deaths in particular groups of workers; this issue is discussed below in relation to Rutherglen, but applies to a lesser extent to the other two locations.

Though our main concern is examination of the lung cancer, some other issues are discussed first. The two deaths from nasal cancer out of a total of 602 deaths occurred in men who had been employed at Rutherglen, which has now closed. Nasal cancer is thus a very minor contribution to the total causes of death; however, even the two deaths were sufficiently increased over the expected value for the difference to be significant $(\mathrm{p}<0.03)$.

At all three factories in Britain there were more other neoplasms observed than expected, though this difference was probably due to chance.

The 39 deaths from bronchitis did not differ significantly from the expected. At Rutherglen, however, there were 31 observed deaths with an expected of only $17.4(p<0.01)$. It is not clear from present data whether this excess at one location is associated in any way with the environment at work, due to other aspects of the behaviour of the workers (increase in smoking etc), or due to the inappropriateness of the application of Scottish national death rates to calculate the expected figure.
There were 365 deaths from other causes, with 295.98 expected $(p<0.001)$. The major difference again occurred at Rutherglen, which makes one think that the Scottish national mortality statistics are inappropriate for calculating the expected figure by cause. Unfortunately simultaneous correction of the expected figures for locality and social class of the workforce was not possible from the data available to us. The mortality of manual workers in Glasgow is probably higher for a wide range of causes than for all men in Scotland. If this is so it would have produced a higher expected figure and a small difference between the observed and expected mortality. The point is supported by the finding that the observed deaths from other causes at Bolton and Eaglescliffe are very close to the calculated expected figures.

A major innovation in this study is the multivariate analysis that has been carried out on several factors that are relevant to the risk of lung cancer. The traditional calculation of person-years at risk and application of national mortality statistics provides an estimate of expected deaths. Pinto et al ${ }^{18}$ used a regression analysis to help unravel the influence of confounding factors when assessing the risk of cancer in workers exposed to arsenic. Their approach, however, was somewhat different as they used (1) continuous data for their independent variables and (2) the standard mortality rate for lung cancer as the dependent variable. The present multivariate analysis uses only the data collected within 
the study, and all scores are binary variables. It compares the risk of developing lung cancer for each given individual from the known data for that individual on the following factors: duration of employment, duration of follow-up, calendar period of employment, factory, age at entry, and estimated degree of chromate exposure. The analysis takes into account the variation of each of these factors together and provides an estimate of the independent contribution from each factor to the risk of lung cancer. It is thus possible to rank these factors in order of importance; the analysis suggests this is duration of employment (overall range 223), duration of follow-up (overall range 206), calendar period of employment (overall range 185), factory (overall range 158), entry age (overall age 70 ), and estimated degree of chromate exposure (overall range 57). The figures in parentheses give the independent contributions to variation from average risk of lung cancer for all the men in the study; the larger the figure, the greater is the contribution of the factor. Because of the method of calculation, these "weights" cannot be directly translated into relative risks - the conventional parameter examined in this type of study and represented by the ratio $\mathrm{O} / \mathrm{E}$ in table 3 . They may be cautiously interpreted, however, as indicating the percentage variation from the average risk of lung cancer in the study. Thus the men with up to nine years' duration of employment have a risk of $59 \%$ below the average, and those working $\mathbf{2 0}$ or more years in the industry have an increase of $164 \%$ above the average-giving an overall variation of $223 \%$ for this factor. One advantage of such an analysis is that it does not require the choice of "standard" death rates to calculate the expected numbers of deaths by cause; this avoids the criticism that the ratio $\mathrm{O} / \mathrm{E}$ is influenced by inappropriate rates, which provides a spurious $\mathrm{E}$. The disadvantage may be that the material cannot be so readily presented in terms of relative risks, statistics that appear (perhaps spuriously) to be easier to interpret.

As might be expected, with increasing duration of employment there was clear evidence of steadily increasing risk of lung cancer-independent of the association of duration of employment with other factors. The second contribution appeared to come from duration of follow-up,'and initially it may be surprising to note that the shorter the period of followup the higher the risk of lung cancer. This is possibly because when an occupational hazard does generate risk of disease, deaths occurring early on after exposure have a relative risk that is much higher than with a longer latent interval-where additional cancers may be swamped by the naturally climbing death rate with advancing age. The third factor was calendar period of employment; the men were categorised into those who had worked only before the plant was modified, both before and after plant modification, and only after plant modification. This analysis shows a clear-cut relationship between calendar period of employment and risk of lung cancer and confirms, independently of all the other factors, that the introduced modifications have been associated with an appreciable decrease in risk of lung cancer. When the factory at which the workers have been employed is considered there appears to be variation, with the Rutherglen factory having an appreciably high risk and the Bolton factory a low risk. Direct explanation of this is not possible in the absence of environmental monitoring.

A small contribution appears to be made by age at entry-and again the ordering of this contribution may seem surprising. There appears to be an increasing relative risk with those who entered work when aged over 40. One possible explanation of this is that an individual who joins the company aged over 40 must have, by definition, a mixed work experience -and he has possibly been exposed to other carcinogens earlier in his career. These carcinogens may, themselves, be responsible for the higher risk, with or without a multiplicative action from exposure to chromate. The workers were classified into the estimated degree of exposure to chromate thought to be entailed in their job description: out of the total of 2636 subjects, 171 of them had been identified as at negligible risk of exposure (those mainly working in the administrative offices). About equal numbers were graded as moderate and major degree of exposure. The analysis suggests that there was definitely a lower relative risk of lung cancer in the negligible exposure group but virtually no difference between the other two categories. This presumably indicates the difficulty of post-hoc categorisation of jobs and the degree of flexibility in duties; workers normally designated as doing one job may, in slack periods, help with other jobs and have very high or very low exposure due to this switch in work.

Bidstrup and Case $^{1}$ had reported a relative excess of lung cancer of 3.6 in the earlier study of men in the chromate-producing industry in Britain. The overall risk of lung cancer of 2.4 shown in table 3 is an average figure based on the experience of all men who have been followed from 1949 to 1977 . The present study differs in two respects: $(a)$ men who left the industry before retirement have now been traced, and $(b)$ the period of study has been extended, thus including younger men who have worked between one and 18 years on plants that have been modified to reduce exposure to airborne chromecontaining materials. This contrasts with the earlier report that included a relatively higher proportion of 
men who had worked for many years in the early part of this century (when environmental control was less stringent). Table 4 provides an up-to-date estimate of the relative risk of lung cancer for those men who have worked only at Eaglescliffe since plant modifications were carried out. This is now about 1.9 and no longer statistically significant and thus compatible with a true value of $1 \cdot 0$. The men traced through GRO and OPCS have been flagged, and further analyses will be carried out to get a more precise estimate and to determine whether this relative risk is further reduced with improvements in working environment. A further analysis of smoking habits of the workforce will also be made.

\section{Addendum}

Table 4 shows two deaths from lung cancer at the Eaglescliffe works after plant modification. One of these men was coded as "low exposure"; cross-check of the man's work record indicates that at no time was he employed on the chrome plant, but worked on the fertiliser plant at the same location.

We are most grateful to L W Grainge for help in compiling the section "The processes in the factories." The follow-up could not have been completed without the help of DHSS, General Register Office, Scotland, and OPCS in tracing leavers from the three factories. It is a pleasure to acknowledge the financial support of the Cancer Research Campaign to the division of epidemiology and the grant from British Chrome and Chemicals Ltd to cover the tracing costs.

\section{References}

${ }^{1}$ Hueper WC. Occupational and environmental cancers of the respiratory system. Berlin: Springer-Verlag, 1966.

${ }^{2}$ Machle W, Gregorius F. Cancer of the respiratory system in the United States chromate-producing industry. Public Health Rep 1948;63:1114-27.

${ }^{3}$ Baetjer AM. Pulmonary carcinoma in chromate workers. Arch Indust Hyg 1950;2:505-16.

4 Brinton HP, Frasier ES, Link Koven A. Morbidity and mortality experience among chromate workers. Public Health Rep 1952;67:835-47.

5 Taylor FH. The relationship of mortality and duration of employment as reflected by a cohort of chromate workers. Am J Public Health 1966;56:218-20.

${ }^{6}$ Enterline PH. Respiratory cancer among chromate workers. JOM 1974;16:523-6.

${ }^{7}$ Watanabe C, Fukuchi Y. An epidemiological survey on lung cancer in workers of a chromate-producing industry in Hokkaido, Japan. International Congress of Occupational Health Abstracts 1975;18:149-50.

${ }^{8}$ Ohsaki Y, Abe S, Kimura K, Tsuneta Y, Mikami H, Murao M. Lung cancer in Japanese chromate workers. Thorax 1978;33:372-4.

9 Bidstrup PL. Carcinoma of the lung in chromate workers. Br J Ind Med 1951;8:302-5.

${ }^{10}$ Bidstrup P, Case RAM. Carcinoma of the lung in workmen in the dichromates-producing industry in Great Britain. Br J Ind Med 1956;13:260-4.

11 Todd GF. Tobacco Manufacturers' Standing Committee Research Papers. No 1 Statistics of smoking in the United Kingdom. 3rd edn. London: Tobacco Research Council, 1962.

12 Hill ID Computing man years at risk. Br J Prev Soc Med 1972;26:132-4.

13 Alderson MR. An introduction to epidemiology. London: Macmillan, 1977. (Revised reprint.)

${ }^{14}$ Alderson MR, Beaven C, Bellas D, Jones DR, Rushton L. Serial mortality tables-neoplastic diseases; England and Wales 1911-75. London: Institute of Cancer Research, 1979. (Magnetic tape version.)

${ }^{15}$ Feldstein MA. A binary multiple regression method of analysing factors affecting peri-natal mortality and other outcomes of pregnancy. Journal of the Royal Statistical Society 1966;129:61-73.

${ }^{16}$ Buckell M, Harvey DG. An environmental study of the chromate industry. Br J Ind Med 1951;8:298-301.

17 Alderson MR. The role of epidemiology in occupational health. In: Gardner AW, ed. Current approaches to occupational health. Bristol: J Wright, 1979:151-86.

18 Pinto SS, Henderson V, Enterline PE. Mortality experience of arsenic-exposed workers. Arch Environ Health 1978; 33:325-31. 